\title{
ALCANCE
}

\section{COLLINS DISTRIBUIDORA: OS DESAFIOS NA GESTÃO DE PESSOAS}

COLLINS DISTRIBUIDORA: CHALLENGES IN THE MANAGEMENT OF PEOPLE COLLINS DISTRIBUIDORA: LOS DESAFÍOS EN LA GESTIÓN DE PERSONAS

\author{
ANA PAULA PEREIRA DOS PASSOS \\ Mestranda \\ Universidade do Vale do Itajaí - Brasil \\ ORCID: 0000-0003-0684-8582 \\ ana.passos@edu.univali.br \\ HELENA WOLLINGER ${ }^{\mathrm{ii}}$ \\ Doutoranda \\ Universidade do Vale do Itajaí - Brasil \\ ORCID: 0000-0002-0434-2687 \\ helena_wollinger@hotmail.com
}

Submetido em: 25/08/2017

Aprovado em: 12/11/2018

Doi: 10.14210.alcance.v26n2(mai/ago).p229-243

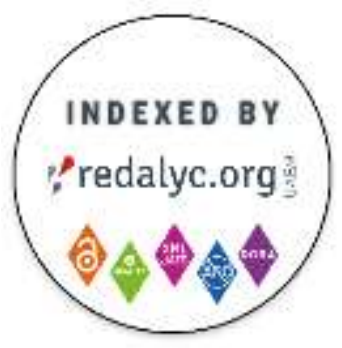

\section{LCENÇA CC BY:}

Artigo distribuído

sob os termos

Creative Commons,

permite uso e

distribuição irrestrita

em qualquer meio

desde que o autor

credite a fonte

original.

(c) (i) 


\title{
RESUMO
}

Este caso para ensino tem por objetivo oportunizar aos alunos a discussão de situações pertinentes à gestão de pessoas por meio da Empresa Collins Distribuidora, relatando suas dificuldades na gestão dos funcionários ao longo do seu crescimento e as consequências acarretadas pela falta de posicionamento dos gestores. Em 2016, após a perda de um dos principais clientes da empresa, Marlon acredita ser o momento propício de discutir sobre a administração de recursos humanos, deste modo convoca os demais sócios, Carlos e Marcos, para uma reunião. É preciso decidir o que fazer e quais as possiviveis soluções, levando em consideração o posicionamento divergente entre os sócios. A proposta é fazer com que os alunos se coloquem no lugar dos gestores, a fim de promover o debate sobre estratégias de curto e longo prazo para os desafios vivenciados pela Collins. Assim, o caso apresenta uma situação na qual o leitor é levado a refletir sobre diversos conceitos inerentes à motivação, ao comprometimento e à produtividade, e relacioná-los com a realidade do mundo corporativo. Propõe-se que o caso seja aplicado nos cursos de Graduação em Administração e Gestão de Recursos Humanos.

Palavras-chave: Recursos Humanos; Motivação; Gestão de Pessoas.

\begin{abstract}
This teaching case study aims to promote discussion among students on situations related to people management through the company Collins Distribuidora, reporting its difficulties in the management of employees throughout the company's growth, and the consequences caused by the lack of positioning of its managers. In 2016, after losing one of its main clients, Marlon, a partner in the company, believes it is now time to discuss its human resources management, so he invites the other partners, Carlos and Marcos to a meeting. They need to decide what to do and what possible solutions, taking into consideration the partners' different positions. The idea is to encourage students to play the role of the managers, in order to stimulate discussion on possible short- and long-term strategies to resolve the challenges that the company faces. The case therefore presents a situation in which the reader is prompted to reflect on various concepts inherent to motivation, commitment and productivity, and to relate them to the reality of the corporate world. It is proposed that the case be applied in the Undergraduate courses in Business Administration and Human Resources Management.
\end{abstract}

Keywords: Human Resources; Motivation; People Management.

\section{RESUMEN}

Este caso para enseñanza tiene por objetivo permitir a los alumnos la discusión de situaciones pertinentes a la gestión de personas a través de la empresa Collins Distribuidora, relatando sus dificultades en la gestión de los funcionarios a lo largo de su crecimiento y las consecuencias acarreadas por la falta de posicionamiento de los gestores. En el año 2016, tras la pérdida de uno de los principales clientes de la empresa, Marlon cree que es el momento propicio para discutir sobre la administración de recursos humanos, de este modo convoca a los demás socios Carlos y Marcos para una reunión. Es necesario decidir qué hacer y cuáles son las posibles soluciones, teniendo en cuenta el posicionamiento divergente entre los socios. La propuesta es hacer que los alumnos se coloquen en el lugar de los gestores para promover el debate sobre estrategias a corto y largo plazo para los desafíos vividos por Collins. Así, el caso presenta una situación en la que el lector es llevado a reflexionar sobre diversos conceptos inherentes a la motivación, compromiso y productividad, y relacionarlos con la realidad del mundo corporativo. Se propone que el caso sea aplicado en los cursos de Graduación en Administración y Gestión de Recursos Humanos.

Palabras-clave: Recursos Humanos; la motivación; Gestión de personas. 


\section{INTRODUÇÃO}

Florianópolis, quinta-feira às dezessete horas, Marlon decidiu reunir-se com seu pai, Carlos, e seu irmão mais velho, Marcos, para discutir sobre os problemas desencadeados durante a semana na empresa, achara ser o momento propício para levantar questões que havia constatado nos últimos anos. A Collins Distribuidora, localizada na Grande Florianópolis, no estado de Santa Catarina, fundada há 30 anos, enfrentava alguns impasses com o crescimento, não conseguia gerir de forma eficiente seus colaboradores, afetando assim a relação com seus clientes.

No ano de 2016, diante da situação da organização, faltas, atrasos, furtos, desvios na rota, erros nas entregas, perda de clientes, era visível a necessidade de mudanças, porém Marlon temia que suas propostas não fossem aceitas por Carlos, que era uma pessoa conservadora, e que durante os últimos anos atuou na gestão dos funcionários do mesmo modo que no estágio inicial da empresa.

Assim, Marlon indagava - Como fazer os colaboradores se comprometerem com a organização? Como instituir as políticas e as normas organizacionais? Como aumentar a produtividade? Como encontrar um equilibrio entre as necessidades e os desejos dos colaboradores e da empresa? - Mas algo Ihe importunava ainda mais - Será que seu pai concordaria em realizar mudanças? Teria ele argumentos para convencer Carlos? Tinha se preparado adequadamente para esta reunião? Como demonstrar que tais decisões seriam primordiais para o sucesso da empresa?

\section{O INÍCIO DA COLLINS DISTRIBUIDORA}

Carlos, fundador da empresa, vem de uma família humilde, desde criança trabalhou na roça ajudando seu pai, Manoel, na produção de hortaliças e vegetais, que eram vendidos no comércio de sua mãe, Rosa. Mais tarde, quando completou 15 anos, começou a distribuir os produtos que excediam a demanda do comércio para outros estabelecimentos do município de Florianópolis, onde residia.

O negócio estava prosperando, Carlos já havia conquistado um número considerável de clientes, foi quando o seu pai faleceu. A morte rápida o desestabilizou emocionalmente e deixou um grande vazio na família. Após o falecimento, ele repensou se daria continuidade ao seu empreendimento, já que não teria condições de cultivar os produtos, distribuílos e captar novos clientes, deste modo vislumbrou nas parcerias com outros produtores um novo modelo de negócio, que se restringiria apenas à distribuição.

Posteriormente, em 1986, já casado, com o negócio estruturado e com clientes nos municípios vizinhos, Carlos fundou sua empresa, chamando-a de Collins Distribuidora, sobrenome da família. Ele adquiriu um depósito, dois caminhões e contratou três funcionários para realização das entregas.

A organização vinha progredindo gradativamente, Carlos era responsável pela gestão da empresa, enquanto sua esposa Cristina era responsável pela área financeira. Carlos fechou acordos com os produtores locais, para que os mesmos trouxessem os produtos pela manhã até a empresa. Com os produtos alocados no depósito, ele organizava os pedidos de acordo com os clientes e os locais de entrega e repassava as rotas e a lista de pedidos para os motoristas.

Os primeiros funcionários foram selecionados de acordo com as relações pessoais de Carlos, o primeiro a ser contratado foi seu irmão mais novo; depois, seu vizinho; e, por último, seu amigo mais próximo. Ele tinha confiança em seus funcionários e durante aquele período a gestão da empresa aparentava ser mais fácil, todos os funcionários trabalhavam por um objetivo comum, tinham entrosamento e boa comunicação.

Apesar dos aspectos que facilitavam a gestão na época, a empresa passou por períodos difíceis em sua história, na década de 80 e 90, com a economia do país se alternando constantemente, a organização permaneceu estagnada durante 10 anos, com o mesmo número de funcionários e realizando apenas pequenas entregas para os municípios mais próximos.

Ainda na década de 90, Carlos teve dois filhos, o mais velho se chamava Marcos e o mais novo Marlon, ambos acompanharam o crescimento gradativo da empresa após o ano de 2000, e logo que completaram 16 anos começaram a trabalhar junto com o pai. Posteriormente, quando finalizaram o ensino médio, os dois optaram pelo curso de graduação em Administração, e a partir de então começaram a atuar de forma mais ativa na gestão da empresa.

Em 2016, a empresa possuía uma frota de 11 caminhões e aproximadamente 220 clientes do mercado alimentício da região da Grande Florianópolis. Tais conquistas se deram pelo trabalho árduo de Carlos e sua família, principalmente por seus filhos, que contribuíram muito com os conhecimentos que estavam adquirindo na graduação para a captação de novos clientes e melhoria de processos. 
As parcerias com fornecedores e produtores agrícolas também foram essenciais para a empresa se destacar entre os concorrentes, principalmente em relação ao preço e à qualidade. No entanto, Marlon e Marcos ainda almejam voos mais altos, como a fidelização e a captação de novos clientes e 0 atendimento de toda a região da Grande Florianópolis.

\section{DEPARTAMENTO DE RECURSOS HUMANOS DA COLLINS}

Ao longo dos seus 30 anos de história, a Collins Distribuidora cresceu gradualmente e, por conseguinte, seu número de funcionários. Porém, foram mantidas durante todo o período as mesmas práticas no que diz respeito à gestão de pessoas. $\mathrm{O}$ departamento de recursos humanos - $\mathrm{RH}$ da empresa se restringia a questões burocráticas, como contratações e desligamentos, não havia um planejamento para a gestão dos colaboradores, integração, motivação, treinamentos formais ou qualquer outra ação.

A organização possuía uma administração familiar, composta por um conselho de sócios que atuava em todas as diretorias e em algumas funções de coordenação. Além dos sócios, a empresa contava com mais 23 funcionários. $\mathrm{A}$ Figura 1 apresenta o organograma da empresa, demonstrando sua hierarquia, assim como sua estrutura.

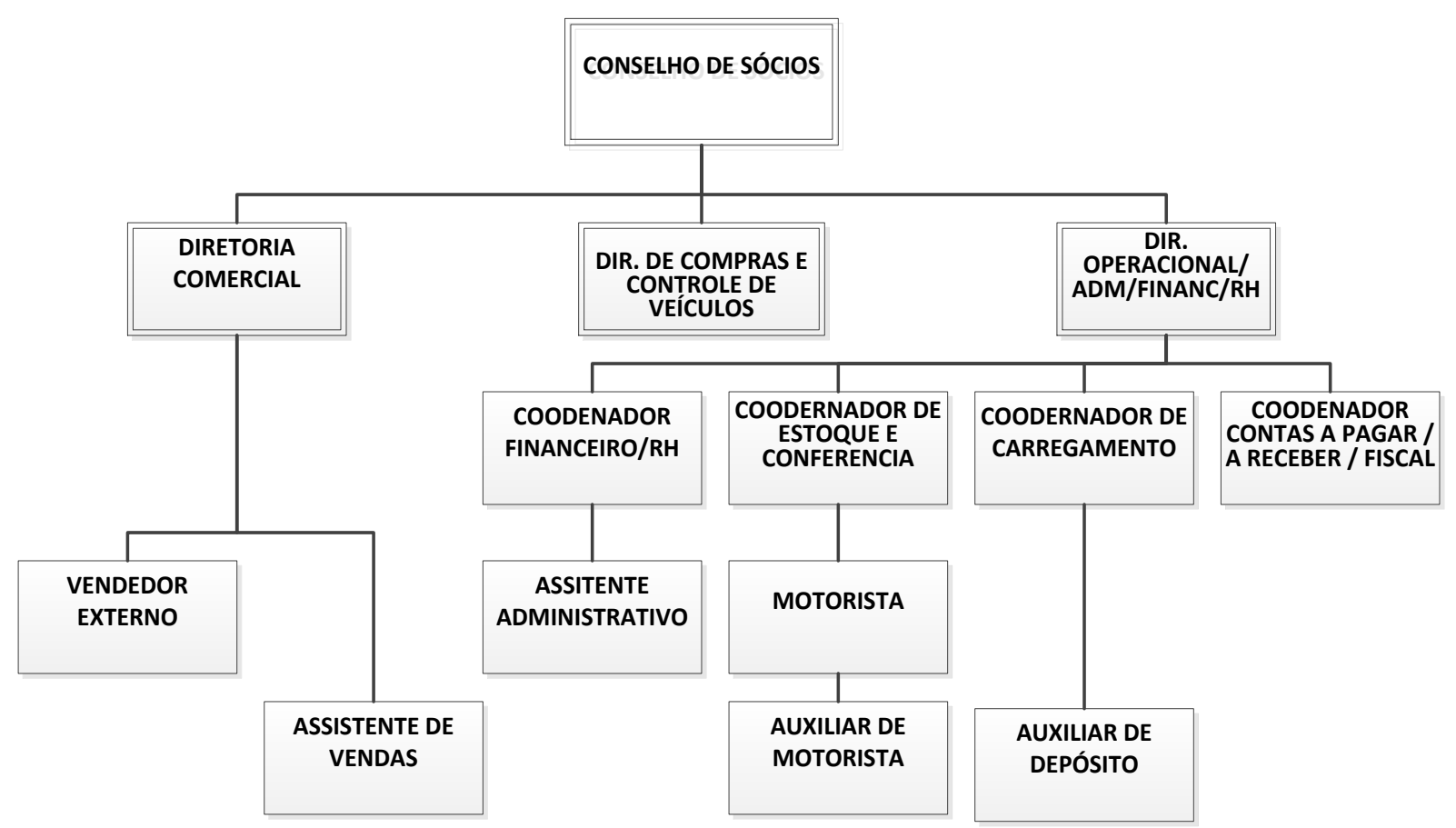

Figura 1. Organograma da Collins Distribuidora Fonte: Dados primários (2018).

Quando um novo funcionário era contratado, em seu primeiro dia de trabalho, Carlos o conduzia até um de seus motoristas e orientava que o mesmo the repassasse as funções, ocasionando assim insegurança ao principiante e perda no controle da transmissão de normas e valores da empresa.

Carlos acreditava que os funcionários tinham que fazer carreira dentro da empresa, assim não contratava motoristas, vendedores, auxiliares administrativos ou assistentes de vendas, estes cargos sempre eram preenchidos por funcionários da casa, apenas eram contratados auxiliares de motorista e de depósito, que são as funções mais baixas da estrutura organizacional.

Deste modo, ele buscava demonstrar sua preocupação, para que os funcionários se sentissem valorizados pelo seu trabalho, incentivando-os a trabalharem corretamente para progredirem dentro da organização. Porém, a ascensão era demorada e os recrutamentos internos não ocorriam com frequência, pois a rotatividade nessas funções era mínima, desse modo, a ação não completava seu objetivo inicial e os funcionários visualizavam este crescimento muito distante. 
No ano de 2016, os critérios de contratação se baseavam na experiência na área de atuação, na recomendação ou na indicação de outros funcionários e no fato de morar próximo à empresa. Todo o processo de divulgação da vaga, entrevista e seleção era realizado por Carlos, sendo que a divulgação ocorria no "boca a boca" e com placas em frente à empresa.

A Collins Distribuidora disponibilizava uma série de benefícios para seus funcionários, como auxílio moradia, em que era pago um valor para o funcionário frente às despesas com sua moradia, sendo que, em alguns casos, quando 0 colaborador era de fora do estado, a empresa oferecia alojamento.

A organização mantinha um restaurante em sua sede, com refeições balanceadas, além disso proporcionava vale alimentação, pagava de forma integral sem desconto em folha. Também era concedido para deslocamento dos profissionais de casa para o trabalho e do trabalho para casa o vale-transporte e o vale combustível. A empresa auxiliava na retirada da $\mathrm{CNH}$ dos ajudantes de motorista e vendia os produtos a preço de custo para seus funcionários.

\section{REPENSANDO A GESTÃO DE PESSOAS}

Em relação ao dia a dia da empresa, era comum os funcionários chegarem atrasados, assinarem o ponto um, dois, três dias depois, não cumprirem a rota estabelecida e atrasarem as entregas, o que acarretava inúmeros problemas para a empresa e aumentava a insatisfação dos seus clientes.

Eram inúmeros os relatos que identificavam a falta de comprometimento dos funcionários com a empresa. Pelo sistema de gerenciamento ter falhas, havia casos de furto de mercadorias por parte dos empregados, sendo que estes furtos só vinham a ser de conhecimento da empresa quando o cliente, ao receber o boleto, ligava para relatar que a quantidade de determinada mercadoria estava errada e solicitava o desconto no boleto.

Nestes casos, o motorista falsificava a assinatura do cliente no canhoto da nota para confirmar que este tinha recebido a mercadoria e relatava ao cliente que não veio o total de mercadorias solicitadas, o motorista pegava uma parte desta mercadoria e revendia. Quando isto ocorria, Carlos primeiro tinha uma conversa franca com os funcionários, questionava os motivos e normalmente concedia mais uma chance de continuar trabalhando na empresa.

Acontecia também com frequência desvios na rota, os motoristas passavam em suas casas, ou realizavam outros afazeres não vinculados à empresa, atrasando as entregas. Marcos defendia a ideia de que os caminhões possuíssem GPS fiscalizado pela empresa, desta forma teriam mais controle sobre seus funcionários. Ainda, havia intrigas entre funcionários, principalmente entre os motoristas no que refere à divisão das rotas, visto que algumas rotas são maiores e mais cansativas do que as outras, alguns não concordavam em fazer uma rota mais complexa que os demais e ganhar a mesma remuneração.

Para Marlon, era necessária uma reestruturação do departamento de RH. Marcos concordava com o irmão, porém acreditava que faltava maior controle e fiscalização. Já Carlos era mais conservador, não gostava de mudanças, os processos na empresa eram todos manuais, apesar de Marcos ter investido em um sistema gerencial, Carlos discordou e não o utilizava.

Como a realidade que Carlos vivenciou era outra e realizou sempre tudo sozinho por anos, era conservador em suas decisões, sempre refletia antes de investir nos planos de seus filhos, que considerava ousados. Quanto à escolaridade, ele só cursou até a quarta série e os conhecimentos foram adquiridos pela experiência. Ele preferia que a empresa continuasse a fazer pedidos, requisições, controle de estoque, entre outras atividades, de forma manual, sem um sistema de gerenciamento, para assim poder continuar gerindo.

Carlos também tinha conhecimento de toda história da organização, sabia que a empresa cresceu sem grandes mudanças, então não via justificativa para que fossem alterados os processos. Achava que não havia necessidade de inovar ou implementar novas tecnologias. Quanto à gestão de pessoas, ele acreditava que a principal motivação para os funcionários era 0 salário, que por meio deste conseguiria mantê-los comprometidos e realizando as tarefas com eficiência.

Já Marcos e Marlon tentavam mostrar para seu pai que os tempos mudaram e o mercado estava acirrado, a concorrência antes era menor e os clientes menos exigentes. Logo, a empresa precisaria se atualizar para manter seus clientes e captar novos. 
Marcos ainda pregava a implementação de novas tecnologias, para melhor controle dos processos, do estoque, dos funcionários, entre outros. Defendia que, por meio destes controles, resolveria a maior parte dos problemas da empresa, pois faria com que os colaboradores se alinhassem com as normas e com os valores da organização e realizassem seu trabalho de forma eficiente. Em uma conversa com Marlon, Marcos disse ao irmão:

- O motivo dos funcionários se atrasarem, saírem da rota e até mesmo furtarem é pelo fato de saber que a empresa não tem nenhum controle que seja capaz de identificar estes desvios. Tenho certeza, Marlon, que se a empresa tivesse mais fiscalização, estes atos não aconteceriam.

- Realmente, Marcos, o controle é essencial, no entanto só teremos funcionários comprometidos se reestruturarmos o departamento de recursos humanos e implementarmos uma gestão de pessoas mais eficiente, que atue no desenvolvimento e na motivação dos funcionários - ressaltou Marlon.

- Sim, seria bom investir também em novas práticas na gestão de pessoas - concordou Marcos.

Ambos sempre discutiam sobre as mudanças que gostariam de realizar na empresa, mas grande parte das conversas não tinha resultado, às vezes até comentavam com Carlos em falas informais, mas pelas rejeições às ideias, não insistiam.

\section{ESTOPIM}

Em uma segunda-feira, os caminhões estavam carregados e as rotas foram repassadas, após algumas horas o diretor geral do Restaurante Caracol, um dos principais clientes da empresa, ligou muito exaltado e disse:

- Eu quero que retire todos os meus próximos pedidos, pois hoje foi a gota d'água! Os seus funcionários não possuem respeito, fui questionar sobre uma possível troca de uma caixa de tomate, pois eles se encontravam amassados, e o motorista discutiu comigo de forma agressiva, largou todas as mercadorias na calçada e saiu. Nossa empresa irá buscar outro fornecedor, já suportamos atrasos, mercadorias trocadas, ainda na semana passada meu restaurante teria um evento importantíssimo e a entrega demorou, como se ainda não bastasse, um dos produtos que utilizaria no prato principal não veio e a justificativa sempre a mesma, que pegaram o pedido errado, tive que de última hora me deslocar até um mercado para comprar o produto. Não quero mais ter que passar por estas situações, é um desrespeito.

Marlon tentou negociar com o cliente dizendo que isto não aconteceria mais, que a partir daquele momento ele daria ainda mais atenção aos pedidos do restaurante, porém o diretor do estabelecimento já havia decidido, disse a ele que o responsável pelo departamento de compras já estava contatando outro distribuidor. A perda desse cliente trouxe um impacto financeiro grande, representava $30 \%$ do faturamento mensal da Collins nos últimos três anos.

Naquela mesma semana, em uma entrevista de desligamento, na qual Marlon estava presente com seu pai, o funcionário relatou a insatisfação com a empresa.

- Sr. Carlos, gostaria de pedir minha demissão - disse o funcionário.

- José, mas o que houve? Aconteceu alguma coisa? - questionou Carlos.

- Estou insatisfeito com o trabalho na empresa, nunca sei exatamente o que é para fazer, parece que eu sempre estou perdido. Acho que todos na empresa trabalham do jeito que querem e que acham melhor, não possuem um padrão em relação ao modo de carregar, de conversar com os clientes, de descarregar os produtos nos estabelecimentos e de fazer pedidos, é como se cada um agisse por conta própria para tentar se sobressair. Além disso, eu nunca sei se estou trabalhando de forma correta ou se eu posso melhorar, em outras empresas que eu trabalhei, eu sabia exatamente o que era para fazer e quando fazer - relatou o funcionário.

Carlos pediu que ele continuasse e que seriam revistas suas objeções, porém o funcionário respondeu que já tinha outra proposta de emprego e que iniciaria no mês seguinte. Durante a conversa, Marlon permaneceu sentado em uma mesa ao lado apenas observando. 0 funcionário desligado estava há quatro meses na empresa, e era um bom profissional, chegava no horário, não faltava, executava as tarefas de forma correta e com agilidade, não havia queixas sobre ele.

Diante da situação, Marlon constatou que era a hora de fazer mudanças, a empresa estava perdendo clientes e funcionários, comprometendo seu crescimento. Ele via que era um momento propício para levantar as questões que havia constatado nos últimos anos na empresa, desse modo, convocou Carlos e Marcos para uma reunião após o expediente. 


\section{DISCUTINDO A REESTRUTURAÇÃO DO DEPARTAMENTO DE RECURSOS HUMANOS}

Florianópolis, quinta-feira às dezessete horas, Marlon estava em sua sala aguardando os demais gestores da empresa, seu pai, Carlos, e seu irmão mais velho, Marcos. Ele estava apreensivo com os resultados e caminhos que a reunião poderia tomar. Após a perda de um dos principais clientes da empresa, Marlon acreditava ser o momento de repensar a gestão de pessoas.

A Collins Distribuidora, fundada há 30 anos, enfrentava alguns empecilhos, pois com um número maior de colaboradores, não estavam conseguindo geri-los de forma eficiente, e isso acarretava diversos problemas que afetavam a relação com seus clientes.

Marlon temia que as mudanças que iria propor não fossem aprovadas por Carlos, pois ele era conservador e durante os últimos anos atuou na gestão dos funcionários do mesmo modo que no estágio inicial da empresa. A reunião iniciou, e Marlon contextualizou todos os problemas da empresa, faltas e atrasos dos empregados, erros e tardança nas entregas, furtos, e a perda de um cliente importante, o Restaurante Caracol. E ainda explicou:

- Todos estes problemas estão impactando em nossos clientes, precisamos melhorar os nossos processos internos, fazer uma gestão de pessoas mais eficiente! Se nosso intuito é captar cada vez mais clientes, temos que proporcionar um diferencial em produto e serviço para que eles se fidelizem à empresa e para que os nossos atuais clientes continuem conosco.

Marcos concordou com o irmão e retratou outros problemas que estavam ocorrendo na empresa, acrescentando que a organização precisa acompanhar o mercado, se informatizar, ter maior controle nos processos. Ele também traz à discussão se a empresa deveria realizar a reestruturação do departamento de pessoal de forma independente, ou contratar um consultor com mais experiência e conhecimento na área para orientar este processo. Marcos ainda comentou:

- Conheci uma empresa que proporciona serviço de consultoria, tive ótimas referências de um amigo, acredito que deveríamos contratar para uma melhor resolução desses problemas. 0 consultor tem maior experiência e conhecimento na área de gestão de pessoas, poderá nos auxiliar neste processo de mudanças.

- Realmente, um consultor para nos auxiliar seria muito útil, pois o mesmo já atuou em diversas empresas, terá uma visão mais ampla e nos trará novas ideias. É um profissional que acompanha o mercado e poderá visualizar tantos problemas como soluções que nós ainda não conseguimos - concordou Marlon.

- Uma pessoa desconhecida entrando na empresa e já tendo acesso a todas as nossas informações. Não concordo com isso, há 30 anos faço a gestão de pessoas assim, não precisamos de mudanças. Além dos altos custos com a contratação de um consultor, é desnecessário e não terá resultados - disse Carlos, um pouco exaltado.

Neste momento, Marlon começou a se questionar: Teriam eles argumentos para convencer Carlos? Tinha se preparado adequadamente para a reunião? Como demonstrar que tais decisões seriam primordiais para o sucesso da empresa? Ainda indagava: - Como fazer os colaboradores se comprometerem com a organização? Como instituir as políticas e as normas organizacionais? Como aumentar a produtividade? Como encontrar um equilíbrio entre as necessidades e os desejos dos colaboradores e da empresa? 


\section{NOTAS DE ENSINO}

\section{OBJETIVOS EDUCACIONAIS E UTILIZAÇÃO RECOMENDADA}

O presente caso tem por finalidade permitir aos alunos vivenciar decisões relacionadas à reestruturação do departamento de recursos humanos, analisando os aspectos gerais da empresa e propondo soluções para uma gestão mais eficiente, em termos de motivação, integração, valorização e comprometimento dos funcionários. A proposta é fazer com que os alunos se coloquem no lugar dos sócios da Collins Distribuidora e discutam estratégias de curto e longo prazo para os desafios que o departamento vivencia. Pretende-se estimular a reflexão e a criatividade para tomada de decisão, portanto se propõe que o caso seja aplicado nos cursos de graduação de Administração e Gestão de Recursos Humanos, em disciplinas de administração de recursos humanos, comportamento humano nas organizações, planejamento estratégico em recursos humanos e psicologia organizacional.

\section{FONTES DOS DADOS}

Este caso de ensino é baseado em fatos reais e, para sua construção, foram utilizados dados primários, coletados por meio de entrevistas presenciais com os sócios da empresa. Os nomes dos personagens e da organização foram alterados para preservar a identidade dos mesmos.

\section{PLANO DE AULA}

Sugere-se que o caso para ensino seja disponibilizado com antecedência mínima de uma semana para leitura prévia dos alunos, assim como indicações de textos que darão base teórica ao entendimento e suporte à análise das questões. Aconselha-se, ainda, que o professor peça aos alunos para que respondam as 4 primeiras questões propostas como atividade, orientando a entregar respostas individuais no dia definido para a discussão, deste modo, o professor poderá avaliar o progresso dos alunos no debate. 0 tempo da aula deve ser dedicado à comparação das avaliações dos alunos, à mesa-redonda, à simulação da reunião e ao esclarecimento das dúvidas que porventura tenham surgido.

$\mathrm{Na}$ aula definida para a discussão, propõe-se que, no início, o professor apresente os conceitos relacionados aos temas abordados no caso em aproximadamente 15 minutos. Após esta breve exposição, aconselha-se que sejam formados pequenos grupos (até 4 pessoas) para discutir as questões previamente respondidas, cada um desses grupos terá que formar um padrão de resposta coletivo. A proposta é que os alunos debatam e discutam as resoluções, analisando e sugerindo soluções. É interessante o professor realizar um sorteio para definir os grupos, promovendo a interação entre a turma e retirando os alunos da zona de conforto.

Posteriormente, as resoluções, a análise e a solução da problemática devem ser apresentadas e discutidas com o grande grupo, o professor deve mediar a discussão, iniciando com o questionamento sobre o dilema principal, a fim de verificar se ficou evidente para todos os alunos qual o problema central do caso. Durante a discussão no grande grupo, o professor deve propor direcionamentos para a análise a partir das opiniões manifestadas pelos alunos, utilizando 0 quadro para elencar os principais fatos, as interpretações e as alternativas propostas por eles, de modo a ficar visível para toda a turma.

Após, recomenda-se a divisão da sala em dois grupos, um grupo deve posicionar-se a favor e outro contra as mudanças no departamento de recursos humanos. Com o intuito de responder à questão 5 , cada equipe deverá fazer um brainstorming. Sugere-se que seja realizada uma simulação da reunião apresentada no caso, em que o grupo 1 deve representar o Sr. Carlos buscando embasamentos e se posicionando de acordo com sua linha de pensamento; já o grupo 2 deve tentar convencer o grupo 1 a reestruturar o departamento de recursos humanos, posicionando-se como Marlon e Marcos.

Por fim, propõe-se que o professor encerre as discussões apresentando o desfecho da reunião, as teorias evidenciadas no caso e avaliando os resultados do aprendizado e da obtenção de feedback dos alunos. Ressalta-se que as sugestões apresentadas poderão ser modificadas a critério do professor. Para a aplicação do caso, propõe-se que 0 horário seja distribuído conforme a Figura 2. 


\begin{tabular}{|l|l|}
\hline Atividade & Duração (em minutos) \\
\hline Breve exposição de conceitos & 15 \\
\hline Organização da turma em pequenos grupos & 5 \\
\hline Resolução das questões em grupo & 30 \\
\hline Discussão das questões no grande grupo & 40 \\
\hline Fechamento das discussões & 10 \\
\hline Divisão da turma em dois grandes grupos & 5 \\
\hline Brainstorming nos grupos & 25 \\
\hline Simulação de reunião & 30 \\
\hline Fechamento das discussões e da exposição das teorias apresentadas no caso & 40 \\
\hline Total & 200 \\
\hline
\end{tabular}

Figura 2. Sugestão de distribuição de horário para aplicação do caso

Fonte: Elaborada pelos autores (2017).

\section{SUGESTÕES DE QUESTÕES PARA DISCUSSÃO}

1. A partir das teorias motivacionais, discuta os métodos utilizados pela empresa Collins Distribuidora.

2. Quais estratégias seriam mais apropriadas para melhorar o comprometimento dos funcionários?

3. Como pode ser estruturado o departamento de Recursos Humanos em uma organização? Quais as estratégias podem ser utilizadas no curto e longo prazo para a melhoria estrutural e dos processos?

4. Dentre as estratégias a serem adotadas, seria viável a empresa contratar um consultor? Quais os benefícios para Collins Distribuidora?

5. Diante do quadro da empresa, você acredita que Marlon e Marcos conseguiram o apoio de Carlos para implementar as mudanças no departamento de $\mathrm{RH}$ ? Destaque as características das duas gerações e quais os argumentos eles deveriam utilizar para convencer o pai?

\section{ANÁLISE DO CASO COM SUPORTE DA LITERATURA}

A sociedade moderna transpassa por uma série de transformações sociais, econômicas, políticas e culturais, que ocasionam num processo de reestruturação produtiva, a fim de garantir competitividade atual e futura para as organizações. Porém, para a obtenção desta vantagem, há uma ênfase nos recursos humanos considerada determinante no processo (Brandão \& Guimarães, 2001).

Neste contexto, as transformações impactaram o ambiente de trabalho, impelindo novos formatos organizacionais, com novas perspectivas quanto ao capital humano (Bastos, 1993). Anteriormente as organizações viam os funcionários apenas como número, e o departamento pessoal atuava de forma formal e mecanicista, restringindo-se a questões burocráticas relacionadas ao trabalhador (Sovienski \& Stigar, 2008).

As mudanças constantes, aliadas à evolução de sindicatos e consequentemente das organizações, ampliou as funções do departamento de recursos humanos, os chamados empregados passam a ser considerados colaboradores e os seus chefes, gestores, as pessoas começaram a ser vistas como um diferencial competitivo e como força impulsionadora dos resultados (Sovienski \& Stigar, 2008).

A gestão de pessoas se caracteriza como um conjunto de políticas e práticas que possibilitam a conciliação de expectativas do contratante e do contratado, para que ambos possam realizá-las a longo prazo (Dutra, 2016). De um lado o departamento defende os interesses da organização, com estratégias voltadas ao negócio e do outro defende os interesses dos colaboradores, compreendendo assim os interesses individuais, organizacionais e coletivos, a fim de promover a interação entre as pessoas e a organização (Gil, 2001).

Nesse sentido, a gestão de pessoas se baseia na ideia de que o desempenho de uma organização depende fortemente da contribuição do capital humano que a compõe, tudo que uma empresa é capaz de realizar, em última análise, depende das pessoas com quem conta (Sovienski \& Stigar, 2008). 


\section{A partir das teorias motivacionais, discuta os métodos utilizados pela Empresa Collins Distribuidora}

A motivação é um algo interno e individual, cada pessoa tem um comportamento motivacional que nasce das necessidades intrínsecas e pode servir-se de fatores externos existentes no meio. Os gestores devem identificar os objetivos de seus colaboradores para formular suas estratégias, com base em teorias motivacionais; há várias teorias, contudo elas não se anulam, ao contrário, elas se complementam (Bergamini, 1990).

Maslow (1943), na teoria da hierarquia das necessidades, considera que a motivação tem como origem os estados de carência do indivíduo e manifesta-se mediante a busca da satisfação destas carências. 0 autor apresenta as necessidades de forma estruturada das mais básicas (fisiológicas e de segurança) às mais avançadas (sociais, de estima e de autorrealização).

Segundo a teoria de Herzberg (1968), há fatores de ordem intrínseca e extrínseca, os de ordem intrínseca, denominados "motivadores", incluem variáveis de caráter mais pessoal, como as de realização, reconhecimento, sentido de responsabilidade, atração, desafio do próprio trabalho, possibilidade de progresso e crescimento psicológico, este fator impacta no desempenho individual do empregado quanto à sua motivação e ao comprometimento (Perez-Ramos, 1990).

Já os fatores extrínsecos, chamados "fatores de higiene", incluem aspectos de natureza preventiva e ambiental, e não são relacionados diretamente com a tarefa ou o trabalho em si mesmo. Estes fatores impulsionam a pessoa a realizar uma ação devido às recompensas, sua ausência gera insatisfação e desconforto no trabalho. Alguns exemplos são normas administrativas, política da empresa, sistemas de salários, condições de trabalho, estilos de supervisão e segurança (Herzberg, 1968; Perez-Ramos, 1990).

Diante destas teorias, pode-se observar que os métodos de motivação utilizados pela empresa Collins Distribuidora não promovem o comprometimento dos funcionários, pois são implementados apenas fatores extrínsecos, como salários, auxílios e vales, que apesar de serem satisfatórios, não causam a motivação, desta forma não impactam no comprometimento afetivo dos mesmos.

O caso evidenciou que faltas, atrasos e erros nas entregas são acontecimentos comuns dentro da organização, deste modo, é preciso repensar as recompensas oferecidas, pois não são as mais adequadas e se concentram apenas em fatores extrínsecos, tendo consequências negativas para a organização. Ressalta-se ainda que os funcionários da empresa se sentem frustrados e não respondem adequadamente às oportunidades e aos incentivos concedidos, não se comprometem com a empresa, não desempenham suas atividades com eficiência e procuram novas oportunidades de trabalho, sendo assim, para que a organização reverta o quadro atual, é necessária a implementação de estratégias motivacionais, ou seja, fatores intrínsecos.

\section{Quais estratégias seriam mais apropriadas para melhorar o comprometimento dos funcionários?}

No que diz respeito ao comprometimento organizacional, este pode ser visto com um elo psicológico entre 0 empregado e a empresa, o qual influencia a decisão de permanência e a colaboração para o alcance de resultados empresariais (Sousa \& Marques, 2014), sua intensidade promove impactos negativos ou positivos tanto no indivíduo quanto na organização (Bastos, 1993).

Neste contexto, o comprometimento é uma relação sólida, ativa e positiva entre indivíduo e empresa, que influencia na sua disposição em oferecer o seu melhor e cooperar com os objetivos organizacionais (Meyer \& Herscovitch, 2001; Mowday, Steers, Porter, 1979), podendo ser caracterizado por no mínimo três fatores: uma sólida convicção e concordância quanto aos valores e aos objetivos da empresa, uma propensão em exercer um esforço considerável em benefício da organização e a aspiração em se manter como membro da mesma (Mowday et al., 1979).

Assim, o comprometimento organizacional tem implicações comportamentais como: assiduidade, pontualidade, intenção e abandono efetivo, absentismo e desempenho individual, sendo imprescindível que a empresa avalie quais resultados pretende alcançar, podendo ser o compromisso com metas gerais ou com objetivos específicos e direcionados (Meyer \& Herscovitch, 2001).

Desta maneira, a Collins Distribuidora precisa identificar inicialmente quais os fatores promovem o comprometimento dos seus colaboradores, embasada em sua cultura, políticas e valores, e considerando 0 relacionamento entre eles e a organização. É essencial examinar os impactos dos sistemas de recursos humanos no comportamento dos funcionários (Meyer \& Allen, 1997). 
Posterior à identificação destes fatores, a empresa deve implementar estratégias e práticas organizacionais que impactem no comportamento e estimulem o comprometimento. Bastos (1994) elenca três grandes conjuntos de técnicas: produtos gerados pelos processos de seleção; treinamento e qualificação; política de reconhecimento e recompensas. Corroborando, outros autores também ressaltam a socialização (Ashforth \& Saks, 1996; Gontijo, 2005), a motivação (Bastos, 1993; Bekin, 1995) e o estilo de liderança (Sá \& Lemoine, 1998).

A socialização promove o comprometimento, pois a aderência pelo novo funcionário dos valores centrais da organização cria uma base de confiança entre o indivíduo e a empresa (Gontijo, 2005). Durante o processo de socialização, as mensagens transmitidas são mais significativas para determinar e fortalecer o comprometimento, visto que os recém-chegados estão em busca de informações (Ashforth \& Saks, 1996).

O treinamento faz parte da dinâmica organizacional e promove uma influência no desenvolvimento de atitudes pós-treinamento dos colaboradores e no seu vínculo com a empresa (Tannenbaum, Mathieu, Salas, Cannon-Bowers, 1991). Este vínculo afetivo dos colaboradores com a empresa possibilita uma atuação mais eficaz e um melhor desempenho em suas tarefas (Santos Filho \& Mourão, 2001).

Ainda neste contexto, o estilo de liderança é outro fator que leva ao comprometimento das pessoas. Um modelo gerencial participativo conduz à aproximação, à confiança e ao respeito entre os membros, motiva a cooperação, a iniciativa dos subordinados e produz um clima harmonioso na organização (Sá \& Lemoine, 1998).

Deste modo, a Collins Distribuidora, além do exposto anteriormente, deve realizar outras ações inerentes à gestão de pessoas, assegurando uma relação mais direta com os funcionários. Os gestores devem rever e fortalecer as relações mantidas, criando práticas gerenciais que tenham impacto sobre o comportamento de seus membros, utilizando formas de recompensar as atitudes de participação de funcionários; estimulando o esforço conjunto, os rodízios de funções, assim como políticas e procedimentos que os aproximem dos objetivos organizacionais (Custódio, Siqueira, Viegas, Pinto, Silva, 2013; Dessler, 1996).

Por fim, a empresa também deve se preocupar com a motivação, pois está diretamente ligada ao comprometimento (Bastos, 1993; Bekin, 1995). Funcionários motivados são mais comprometidos, a Collins Distribuidora pode criar estratégias que promovam reconhecimento, crescimento profissional, autorrealização e fornecer feedback a seus funcionários.

\section{Como pode ser estruturado o departamento de Recursos Humanos em uma organização? Quais as estratégias podem ser utilizadas no curto e longo prazo para a melhoria estrutural e dos processos?}

Para uma empresa reestruturar o seu departamento de recursos humanos e implantar práticas de gestão de pessoas, inicialmente toda equipe deste departamento precisa buscar desenvolvimento, seja por meio de cursos, congressos ou coaching (Mattos et al., 2013). Ressalta-se que o envolvimento de todos os colaboradores é necessário neste processo para a realização de mudanças sólidas, e que a equipe precisa trabalhar um novo conceito de gestão (Mattos et al., 2013).

Na empresa Collins Distribuidora, assim como nas demais organizações, a realização de uma reestruturação eficiente no departamento deve contar com um plano de ações a ser implementado no curto e longo prazo. 0 planejamento de curto prazo remete a planos a serem cumpridos dentro de um curto período de tempo, já o planejamento de longo prazo refere-se a planos a serem implementados futuramente (Mattos et al., 2013). Estes planos que serão desenvolvidos pelo departamento devem estar alinhados às estratégias organizacionais (Oliveira \& Limongi-França, 2005).

Em relação aos planos de curto prazo, o setor precisa especificamente se dividir em duas frentes de trabalho, 0 operacional, que ficaria responsável pela parte burocrática; e o estratégico, que atuaria no desenvolvimento humano e organizacional, aplicando práticas de comunicação interna, feedback, premiação, reconhecimento, clima, cultura, qualidade de vida no trabalho, entre outros (Mattos et al., 2013). Na Collins, a parte estratégica poderia ter como responsável Marlon, já que o mesmo apresenta características eminentes à função.

Para a aplicação das práticas de gestão de pessoas, seria necessário avaliar o quadro atual da empresa, para após definir os planos. De acordo com as características da Collins Distribuidora expostas no caso, apontam-se como ações viáveis: o oferecimento de treinamentos, os métodos de integração, as novas propostas de recompensas, os reconhecimentos por tarefas bem executadas, o enfoque no desenvolvimento profissional e a disponibilização da missão, da visão, dos valores e das diretrizes da empresa aos colaboradores. 
Além disso, a empresa poderia investir em um ponto eletrônico para ter mais controle sobre os atrasos e as faltas, e disponibilizar um prêmio de assiduidade mensalmente, para reconhecer os funcionários que cumprem seus horários com regularidade, comprometimento e dedicação. Quanto à qualidade de vida, sugere-se ainda que a Collins realize ações no que tange à dimensão física, emocional, social, intelectual e organizacional, motivando seus colaboradores e estimulando a criatividade, 0 autodesenvolvimento e a autonomia.

Para a elaboração dos planos de longo prazo, a gestão de pessoas precisaria ter como objetivos o desenvolvimento e a criação de valor compartilhado, a inovação no negócio, a promoção, a disseminação de conhecimentos, a comunicação interna, o planejamento de carreiras e a capacitação dos colaboradores (Mattos et al., 2013). Desse modo, as práticas criadas pelo departamento precisam estar relacionadas com o mesmo.

A Collins poderia criar um manual de trabalho com todas as informações da empresa, como história, missão, valores, diretrizes, seus produtos e descrição de cargos, especificando os métodos de trabalho e a relação entre as funções, a fim de guiar seus colaboradores para o alcance dos objetivos organizacionais. Também seria interessante implantar um plano de cargos e salários, orientando os funcionários quanto as suas atividades e alocando os recursos humanos conforme os intuitos da empresa (Oliveira, 2000).

Ainda como sugestão, propõe-se o estabelecimento de um programa de metas para os colaboradores, por exemplo, os vendedores poderiam ter metas de captação de novos clientes mensais; e os motoristas e ajudantes, metas inerentes ao tempo e à qualidade da entrega. Outra prática que pode ser aplicada é o feedback, essa técnica propicia o desenvolvimento de habilidades e o fortalecimento de relações, impactando no desempenho e nos resultados da empresa (Turci, 2013).

Como métodos para avaliação de desempenho, a empresa poderia inserir uma gestão de desempenho com avaliações $360^{\circ}$. Assim, acompanharia os funcionários individualmente e obteria uma base de dados para futuras promoções. Como outras ações para implementação em longo prazo, citam-se 0 investimento nas habilidades e nos conhecimentos dos colaboradores, uma pesquisa de clima organizacional, a identificação de fatores que afetam o bemestar, a motivação e a satisfação dos colaboradores e a implantação de uma comunicação interna clara que garanta total assimilação dos valores e dos princípios da organização.

Por fim, ressalta-se que a Collins Distribuidora precisa inovar os processos de recursos humanos. A empresa tem de facilitar a comunicação, para que por meio das críticas e das sugestões possa realizar melhorias contínuas. Quanto à forma de gestão, a liderança tem que ser capaz de promover condições favoráveis para engajar os colaboradores, atribuindo novos mecanismos de motivação aos profissionais (Mattos et al., 2013). É importante monitorar e avaliar constantemente os resultados após a implementação dos planos para verificar se estão de acordo com o que foi planejado (Oliveira \& Limongi-França, 2005).

\section{Dentre as estratégias a serem adotadas, seria viável a empresa contratar um consultor? Quais os benefícios para Collins Distribuidora?}

A consultoria é um trabalho colaborativo de diagnóstico, aconselhamento e orientação, em que o gestor e o consultor atuam em conjunto em busca da melhoria da organização, objetivando sistematizar informações para determinar um plano de soluções ou de redução dos problemas (Jacintho, 2004). Deste modo, o processo compreende pesquisa, reflexão, subsídio e apoio aos gestores, a fim de integrar as variáveis humanas, ambientais e organizacionais, além de otimizar técnicas e estratégias pertinentes à administração (Oliveira, 2000).

Neste contexto, a consultoria é atrativa a qualquer empresa que apresente problemas e dificuldades em lidar com eles, porém o empresário precisa verificar a necessidade e reconhecer os benefícios desta intervenção (Jacintho, 2004). Como principais benefícios que uma consultoria pode fornecer à administração de recursos humanos, Oliveira (2000) cita: conhecimento, atualização, fornecimento de novas metodologias, elucidação dos objetivos da organização, melhoria no processo de aprendizagem interna, alinhamento estratégico da gestão com os valores organizacionais e mercado de trabalho, introdução e assimilação da cultura e melhoria no clima organizacional (Oliveira, 2000).

Assim, conclui-se que é viável a contratação de uma consultoria para a Collins Distribuidora, pois a contratação poderá contribuir com a restruturação do departamento de recursos humanos e reorganização da empresa. Na consultoria serão realizadas a identificação de problemas, a implantação de novos métodos e soluções de forma eficiente. Vale ressaltar que, pelo fato de Marlon e Marcos não possuírem experiência prática para este processo, a contratação de um consultor seria ideal, pois este profissional tem as competências e as habilidades necessárias, além de possuir experiência prática na área. 
5. Diante do quadro da empresa, você acredita que Marlon e Marcos conseguiram o apoio de Carlos para implementar as mudanças no departamento de RH? Destaque as características das duas gerações e quais os argumentos eles deveriam utilizar para convencer o pai?

No contexto corporativo, torna-se relevante compreender as diferentes gerações, comparando como cada uma delas se inter-relaciona, sua maneira de agir, pensar, suas crenças, valores, ideologias, prioridades e características (Andrade, Mendes, Correa, Zaine, Trimer-de-Oliveira, 2012; Chiuzi, Peixoto, Fusari, 2011). Nesse sentido, para compreensão dos personagens do caso, faz-se necessário um levantamento das características das duas gerações, conforme se apresenta na Figura 3.

\begin{tabular}{|c|l|}
\hline Geração & Características \\
\hline $\begin{array}{c}\text { Geração baby boomers - } \\
\text { Nascidos até 1964 }\end{array}$ & $\begin{array}{l}\text { São motivados, comprometidos, leais, otimistas, conservadores e valorizam o status e a } \\
\text { ascensão profissional dentro da organização. }\end{array}$ \\
\hline $\begin{array}{c}\text { Geração Y - } \\
\text { Nascidos de 1978 em diante }\end{array}$ & $\begin{array}{l}\text { São multifacetadas, inovadores, com uma inteligência associada ao coletivo, vivem em } \\
\text { ação, são rápidos, imediatistas, têm domínio das tecnologias, possuem uma visão } \\
\text { sistêmica, aceitam a diversidade e se conectam a inúmeras pessoas. }\end{array}$ \\
\hline
\end{tabular}

Figura 3. Comparativo entre as gerações

Fonte: Elaborada pelos autores com base em Comazzetto et al. (2016)

Por meio das características da geração baby boomers e observando as qualidades e os aspectos positivos da atuação do gestor fundador, pode-se verificar no decorrer do caso que Carlos é conservador, motivado e comprometido com a organização, valoriza a ascensão profissional dentro da empresa, realizando processos seletivos internos e contratação externa apenas de cargos mais baixos.

Em comparativo com as características da nova geração, ou seja, Marcos e Marlon, e considerando a participação deles na empresa e os aspectos positivos de sua gestão, como a inserção de tecnologias e a captação de novos clientes, além do comprometimento com a Collins, os alunos podem se posicionar sobre o desfecho da reunião, e defender se Marlon e Marcos conseguirão ou não o apoio de Carlos.

Em relação aos argumentos, Marlon e Marcos precisam explanar todos os benefícios eminentes à contratação do consultor para a empresa, evidenciando os problemas ocasionados pela falta de gestão de pessoas e os impactos a curto e longo prazo para a organização. Eles também precisam deixar claro que o custo se torna pequeno frente aos resultados que serão alcançados ao longo prazo, que as informações da empresa ficaram em sigilo, que o planejamento ocorre em conjunto e que a aceitação das propostas e das decisões são exclusivamente dos gestores.

\section{DESFECHO DA REUNIÃO}

Marlon e Marcos discutiram com Carlos sobre a contratação do consultor, apresentando exemplos e resultados de outras empresas, após explanaram também os diversos problemas que a Collins Distribuidora estava enfrentando e seus impactos negativos. Depois de algumas horas de reunião, Carlos enfim concordou com a contratação, porém ressaltou que não se envolveria no processo e que ambos ficariam responsáveis.

Logo após, Marcos marcou uma reunião com o consultor, em que foram repassadas todas as informações referentes à empresa e aos problemas identificados. 0 consultor, por sua vez, apresentou algumas propostas para a implementação. Nos meses seguintes, várias mudanças ocorreram na Collins Distribuidora, o consultor esteve presente na empresa semanalmente acompanhando e auxiliando todo o processo. Além das questões relacionadas à gestão de pessoas, foi revisto também o sistema financeiro da empresa.

Quanto às ações já implementadas, foram disponibilizados uniformes e crachás, definidas novas regras em relação ao ponto, novas normas e políticas para empresa, criado um manual para organização com história, visão, valores, normas, detalhamento das funções e perfil do profissional e implantado o benefício de assiduidade para os colaboradores que não faltam e não chegam atrasados no trabalho. Além disso, estão sendo realizadas reuniões com toda a empresa, para que todos tenham consciência das mudanças que estão ocorrendo e dos objetivos. Marlon está efetuando feedback com os colaboradores de forma individual e mensal, enquanto Carlos, após o convívio com 0 consultor, modificou alguns dos seus conceitos e sugeriu que Marlon ficasse responsável pelos recursos humanos. 


\section{REFERÊNCIAS}

Andrade, S. I., Mendes, P., Correa, D. A., Zaine, M. F., \& Trimer-de-Oliveira, A. (2012). Conflito de gerações no ambiente de trabalho: um estudo em empresa pública. Proceedings of the International Conference on Information Systems and Technology Management, São Paulo, SP, Brasil, 9.

Ashforth, B. K., \& Saks, A. M. (1996). Socialization tactics: Longitudinal effects on newcomer adjustment. Academy of Management Journal, 39(1), 149-178.

Bastos, A. V. B. (1993). Comprometimento organizacional: um balanço dos resultados e desafios que cercam essa tradição de pesquisa. Revista de Administração de Empresas, 33(3), 52-64.

Bastos, A. V. B. (1994). Comprometimento organizacional: a estrutura dos vínculos do trabalhador com a organização, a carreira e o sindicato. Tese de doutorado em Psicologia, Instituto de Psicologia, Universidade de Brasília, BSB, Brasil.

Bekin, S. F. (1995). Conversando Sobre Endomarketing. São Paulo: Makron Books.

Bergamini, C. W. (1990). Motivação: mitos, crenças e mal-entendidos. Revista de Administração de Empresas, 30(2), 23-34.

Brandão, H. P., \& Guimarães, T. D. A. (2001). Gestão de competências e gestão de desempenho: tecnologias distintas ou instrumentos de um mesmo construto? Revista de Administração de Empresas, 41(1), 8-15.

Chiuzi, R. M., Peixoto, B. R. G., \& Fusari, G. L. (2011). Conflito de gerações nas organizações: um fenômeno social interpretado a partir da teoria de Erik Erikson. Temas Psicologia, 19(2), 579-590.

Comazzetto, L. R., Vasconcellos, S. J. L., Perrone, C. M., \& Gonçalves, J. (2016). A Geração Y no Mercado de Trabalho: um Estudo Comparativo entre Gerações. Psicologia Ciência e Profissão, 36(1), 145-157.

Custódio, L., Siqueira, C., Viegas, G. L. A. U. C. E., Pinto, V., \& Silva, R. D. (2013). Comprometimento organizacional e estratégias de gestão de pessoas: uma análise das experiências em organizações públicas brasileiras. Anais do Seminários em Administração, São Paulo, SP, Brasil, 16.

Oliveira, P. M., \& Limongi-França, A. C. (2005). Avaliação da gestão de programas de qualidade de vida no trabalho. RAE-eletrônica, 4(1), 1-21.

Dessler, G. (1996). Conquistando comprometimento. São Paulo: Makron Books.

Dutra, J. S. (2016). Gestão de Pessoas: modelo, processos, tendências e perspectivas (2a ed). São Paulo: Atlas.

Gil, A. C. (2001). Gestão de pessoas: enfoque nos papéis profissionais. São Paulo: Atlas.

Gontijo, C. L. (2005). Socialização, cultura e constituição do sujeito organizacional: um estudo de caso. Gestão e Conhecimento, 1(1), 1-19.

Herzberg, F. (1968). One more time: How do you motivate employees? Harvard Business Review, 46(1), 36-44.

Jacintho, P. R. B. (2004). Consultoria Empresarial: procedimentos para aplicação em micro e pequenas empresas. Dissertação de mestrado em Engenharia da Produção, Programa de Pós-Graduação em Engenharia da Produção, Universidade Federal de Santa Catarina, Florianópolis, SC, Brasil.

Maslow, A. H. (1943). A theory of human motivation. Psychological Review, 50(4), 370-396.

Mattos, A.; Cunha, D. R., Andrade, E. L., Silva, J. J., Santos, L. C. R., Woehl, S., Martins, P. F., Catapan, A. (2013). Proposta de reestruturação de uma organização: Mudança no processo de departamento pessoal para práticas de gestão de pessoas. Espacios, 34(12), 21-32. 
Meyer, J. P., \& Allen, N. J. (1997). Commitment in the workplace: theory, research and application. Thousand Oaks, CA: Sage Publications.

Meyer, J. P., \& Herscovitch, L. (2001). Commitment in the workplace: Toward a general model. Human resource Management Review, 11(3), 299-326.

Mowday, R. T., Steers, R. M., \& Porter, L. W. (1979). The measurement of organizational commitment. Journal of Vocational Behavior, 14(2), 224-247.

Oliveira, R. (2000). Contribuições das consultorias externas para a administração de recursos humanos: um estudo nas indústrias de grande porte de Joinville. Dissertação de Mestrado em Administração, Universidade Federal de Santa Catarina, Florianópolis, SC, Brasil.

Pérez-Ramos, J. (1990). Motivação no trabalho: abordagens teóricas. Psicologia USP, 1(2), 127-140.

Sá, M. A. D., \& Lemoine, C. (1998). O estilo de liderança como fator de comprometimento na empresa. Anais do Encontro Nacional da Associação Nacional de Pós-graduação e Pesquisa em Administração, Foz do Iguaçu, PR, Brasil, 22.

Santos Filho, G. M. D., \& Mourão, L. (2011). A relação entre comprometimento organizacional e impacto do treinamento no trabalho. Revista Psicologia Organizações e Trabalho, 11(1), 75-89.

Sousa, E. P., \& Marques, A. L. (2014). Comprometimento Organizacional e Personalidade: considerações sobre a influência dos traços no comprometimento. Anais do Encontro Nacional da Associação Nacional de Pósgraduação e Pesquisa em Administração, Rio de Janeiro, RJ, Brasil, 38.

Sovienski, F., \& Stigar, R. (2008). Recursos humanos x gestão de pessoas. Revista Cientifica de Administração, 10(10), $51-61$.

Tannenbaum, S. I., Mathieu, J. E., Salas, E., \& Cannon-Bowers, J. A. (1991). Meeting trainees' expectations: The influence of training fulfillment on the development of commitment, self-efficacy, and motivation. Journal of Applied Psychology, 76(6), 759-769.

Turci, R. H. (2013). Feedback: a importância desta técnica na rotina empresarial. Revista Interatividade, 1(1), 81-89.

\footnotetext{
i Bolsista de PROSUC/CAPES - Modalidade 1

ii Bolsista PROSUC/CAPES - Modalidade 1
} 